\title{
Análisis de ciclo de vida y reglas de categoría de producto en la construcción. El caso de las baldosas cerámicas
}

\author{
Life cycle assessment and product category rules for the \\ construction sector. The floor and wall tiles sector case study
}

$\underline{\text { G. Benveniste }}^{(*)}$, C. Gazulla ${ }^{(*)}$, P. Fullana ${ }^{(*)}$, I. Celades $^{(* *)}$, T. $\operatorname{Ros}^{(* *)}$, V. Zaera ${ }^{(* *)}$, B. Godes ${ }^{(* * *)}$

RESUMEN

El presente trabajo muestra la evolución de las actividades de Análisis de Ciclo de Vida (ACV) y redacción de las Reglas de Categoría de Producto (RCP) en el sector de la construcción, más concretamente para los recubrimientos cerámicos. En particular, se presentan los resultados obtenidos a partir del estudio de ACV de las baldosas cerámicas a nivel sectorial, que ha servido como base para la redacción de las correspondientes RCP, necesarias para la edición de Declaraciones Ambientales de Producto (DAP). Más de 50 empresas españolas fabricantes de baldosas cerámicas han participado en el estudio suministrando datos de inventario sobre la fabricación de sus productos. Adicionalmente, se ha utilizado información bibliográfica y la base de datos del programa informático GaBi-4 de PE International ${ }^{1}$ para datos genéricos como producción de energía o transporte.

Las DAP son declaraciones voluntarias basadas en estudios de ACV que permiten la difusión de información ambiental cuantificada sobre el ciclo de vida de un producto. El desarrollo de estos estudios de ACV se debe realizar siguiendo unas determinadas Reglas de Categoría de Producto. En la redacción del borrador de las RCP de materiales de recubrimientos cerámicos se han seguido las normas UNE EN ISO 14025 e ISO 21930 y se ha sometido a un trámite de exposición pública a empresas fabricantes y asociaciones empresariales. Dichas RCP se han desarrollado en el marco del sistema DAPc, promovido por la Generalitat de Catalunya y el CAATEEB ${ }^{2}$ y constituye el primer sistema de ecoetiquetado de productos de la construcción en España.

630-6

Palabras clave: Azulejo, Gres, Análisis de Ciclo de Vida, Reglas de Categoría de Producto, Declaraciones Ambientales de Producto

\section{SUMMARY}

This paper illustrates the Life Cycle Analysis (LCA) activities performed during the preparation of the Spanish Product Category Rules (PCR) relative to the construction sector. Specifically, the study presents the results obtained from the life cycle analysis of the floor and wall tile sector, which served as the basis for the drafting of the PCR required for the definition of Environmental Product Declarations (EPD). More than 50 Spanish companies in the ceramic tile sector participated in the study, providing inventory data on the manufacture of their products. Additionally, bibliographic information and the GaBi 4 software database by PE International were used to complete background and generic data, such as those related to energy and transportation processes.

EPDs are voluntary declarations based on LCA studies that permit the disclosure and dissemination of environmental information quantified over the life cycle of a product. The definition of PCRs for ceramic tiles was performed in accordance to the UNE EN ISO 14025 and ISO 21930 standards and they have been submitted to industries and professional association public consultations. PCRS have been developed in the context of the DAPC program (promoted by the Catalan Government and (AATEEB) and represents the first ecolabelling activity for building products in Spain.

Keywords: Wall tiles, floor tiles, Life Cycle Assessment, Environmental Product Declaration, Product Category Rules
Informes de la Construcción Vol. 63, 522, 71-81, enero-marzo 2011 ISSN: 0020-0883 elSSN: 1988-3234 doi: 10.3989/ic.10.034

\footnotetext{
$\left(^{*}\right)$ (ESCl), Universitat Pompeu Fabra, Barcelona, (España)

(**) ITC, Universitat Jaume I. Castellón. (España)

${ }^{* * *}$ ) Asociación Española de Fabricantes de Azulejos y Pavimentos Cerámicos (ASCER). (España)

Persona de contacto / Corresponding autor: gabriela.benveniste@esci.es (G. Benveniste)
}

Fecha de recepción: 16-04-10 Fecha de aceptación: 05-10-10 


\section{INTRODUCCIÓN}

Durante los últimos años, en el seno de la comunidad profesional del sector de la construcción ha aumentado el interés por conocer y reducir el impacto ambiental provocado por la utilización de determinados materiales en la edificación, con el objetivo de promover una construcción más sostenible y respetuosa con el entorno, utilizando la metodología del Análisis de ciclo de vida (ACV) u otras metodologías para la definición de los impactos ambientales (1). Las baldosas cerámicas, como cualquier producto de origen industrial, generan una serie de impactos ambientales a lo largo de todo su ciclo de vida. Puede decirse que el enfoque de ciclo de vida es la aproximación más apropiada para analizar y evaluar dichos impactos y conseguir así centrar esfuerzos para su reducción. De esta manera, también se consigue mejorar la sostenibilidad del producto y ser más competitivo frente a otros productos ya existentes en el mercado con una aplicación similar o productos emergentes.

El enfoque de ciclo de vida permite tratar los aspectos ambientales más allá de los límites locales de los sistemas analizados, evitando el problema de posibles desplazamientos a lo largo de los procesos de la cadena de producción o de diferentes categorías de impacto. Así, por ejemplo, a menudo determinadas soluciones constructivas se presentan como "ecológicas" porque mejoran aspectos ambientales muy concretos en determinadas etapas del ciclo de vida de los edificios -como puede ser su fabricación-. Sin embargo, cuando son analizadas de una manera más integrada y se consideran otras etapas del ciclo de vida-como su utilización, mantenimiento o disposición final-, estas soluciones pierden sus ventajas en comparación a otras. El enfoque de ciclo de vida ayuda a la toma de decisiones con rigor científico a la hora de escoger las mejores tecnologías disponibles y minimizar desde su diseño el impacto ambiental de los productos.

En este contexto, GiGa (ESCI-UPF) y el ITC (Instituto de Tecnología Cerámica de la Universidad Jaume I) y a petición de ASCER (Asociación Española de Fabricantes de Azulejos y Pavimentos Cerámicos), han desarrollado un estudio de ciclo de vida de las baldosas cerámicas a nivel sectorial siguiendo las normas ISO sobre ACV (UNE EN ISO 14040:2006 (2) y UNE EN ISO 14044:2006 (3). La referencia completa de las normas citadas está incluida

1 http://www.gabi-software. com/gabi/gabi-4/

${ }^{2}$ Col.legi d'Aparelladors, Arquitectes Tècnics i Enginyers de l’Edificació de Barcelona para las baldosas cerámicas, necesarias para la preparación de las Declaraciones Ambientales de Producto (DAP) -también Ilamadas EPD (Environmental Product Declarations) o ecoetiquetas tipo III según la clasificación de ISO-. Estas DAP permiten la divulgación y difusión de información ambiental cuantificada sobre el ciclo de vida de un producto obtenida a través de un ACV.

La redacción de estas RCP ha seguido las normas UNE EN ISO 14025 (5) e ISO 21930 (6), teniendo siempre en cuenta los comentarios aportados por las empresas fabricantes de baldosas cerámicas. Éstas se han desarrollado en el marco del sistema DAPc (promovido por la Generalitat de Catalunya y CAATEEB) y representa el primer sistema de ecoetiquetado de productos de la construcción en España.

El presente proyecto ha sido realizado a petición de ASCER mediante el apoyo financiero del IMPIVA (GeneralitatValenciana) y los Fondos FEDER, a través de los Planes Sectoriales de Competitividad.

\section{ACV SECTORIAL DE LAS BALDOSAS CERÁMICAS}

\subsection{Metodología de análisis de ciclo de vida}

El Análisis de Ciclo de Vida es una herramienta válida para determinar, clasificar y cuantificar los impactos ambientales de un producto o actividad a lo largo de todo su ciclo de vida, desde la extracción de las materias primas que lo constituyen hasta que se convierte en un residuo (es por ello, que también es conocido como el análisis "desde la cuna a la tumba").

Tal y como queda reflejado en la norma UNE EN ISO 14040, la metodología ACV permite determinar los aspectos ambientales y los impactos potenciales asociados a un producto a lo largo de su ciclo de vida: compilando un inventario de las entradas y salidas relevantes del sistema; evaluando los impactos potenciales asociados a estas entradas y salidas e interpretando los resultados de las fases de inventario e impacto en relación a los objetivos del estudio. El ACV se estructura en cuatro grandes fases $(7,8)$ (figura 1 ):

- Definición de objetivos y alcance del estudio: Incluye tanto la definición exacta del sistema a estudiar, como el alcance y la profundidad del estudio.

- Análisis de inventario: recogida de datos para cuantificar las entradas y salidas de materia y energía del sistema de estudio definido en la fase anterior. Se debe Ile- 
gar hasta los flujos elementales, es decir, las entradas y salidas directas al medio natural.

- Evaluación de impacto: identificación, caracterización y cuantificación de los efectos sobre el medio ambiente del sistema estudiado.

- Interpretación de los resultados: se identifican los puntos significativos basados en los resultados obtenidos en la fase nterior, verificando su integridad, sensibilidad y coherencia. Además se añaden las conclusiones del estudio así como sus limitaciones y recomendaciones.

El ACV se utiliza habitualmente para identificar los principales elementos de un sistema que se deberían mejorar para disminuir su impacto ambiental a escala global, esto permite optimizar los esfuerzos destinados a tal fin. También es común utilizar esta herramienta para comparar alternativas o para estimar los efectos potenciales que puede tener un cambio en el diseño de un producto o sistema.

Otra de las aplicaciones más comunes del ACV es el cálculo de la "huella de carbono" (Carbon Footprint) de los productos o servicios, que coincide con el Potencial de Calentamiento Global (Global Warming Potential, GWP), es decir la cantidad de emisiones totales de gases de efecto invernadero asociadas al sistema analizado, siendo la unidad de medida los kg de dióxido de carbono equivalente $\left(\mathrm{CO}_{2}\right.$-eq. $)$.

\subsection{Objetivos y alcance}

El estudio de análisis de ciclo de vida de la baldosa cerámica a nivel sectorial, ha permitido identificar los aspectos ambientales prioritarios para identificar y, justificar qué estrategias serían ambientalmente preferibles en el caso particular del mercado español para el ecodiseño de estos productos, favoreciendo el diseño de productos más respetuosos con el medio ambiente, y/o más sostenibles desde un punto de vista medioambiental. En esta fase de la metodología, deben definirse claramente las características funcionales del producto que se está estudiando. La función principal de las baldosas es la de pavimentar (suelos) o revestir (paredes). En el primer caso se aconseja utilizar gres, dadas sus características mecánicas, mientras que para el recubrimiento de paredes se aconseja el uso de azulejos (9), no obstante, dada la gran versatilidad de las baldosas cerámicas y el avance alcanzado en cuanto a propiedades técnicas, es posible utilizar el gres para revestir paredes.

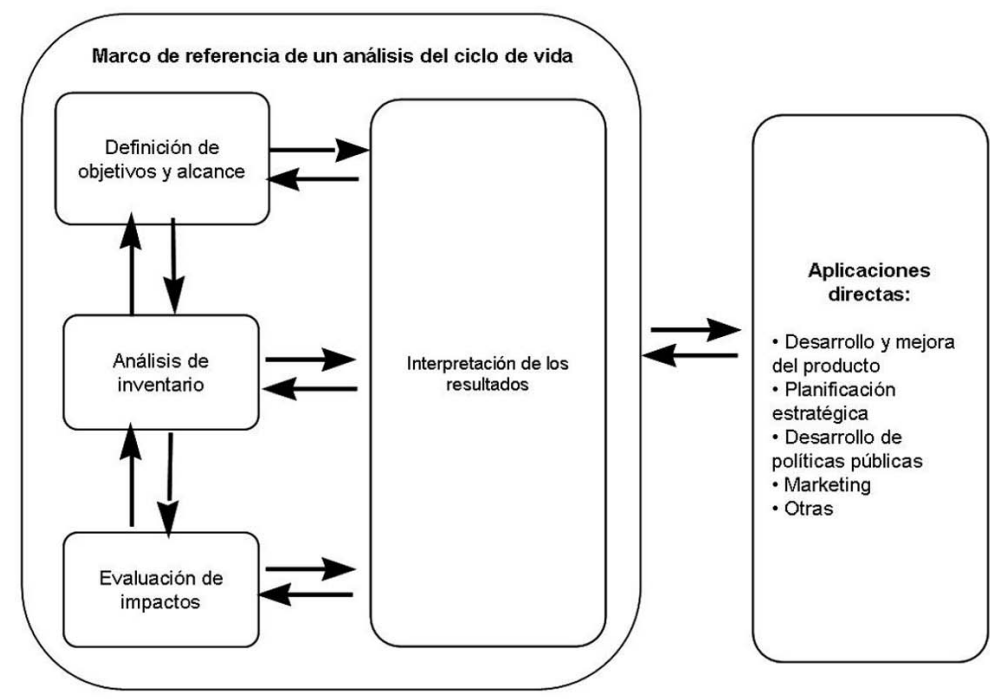

Fuente: UNE-EN ISO 14040-2006

La unidad funcional cuantifica las funciones identificadas que son objeto de estudio. Todos los datos del sistema (tanto las entradas y salidas de materia y energía), deben ir referidos a un flujo de referencia que dé respuesta a esta unidad funcional. Además, la unidad funcional permite la comparación cuando se analizan distintos sistemas. En este estudio, la unidad funcional consiste en el "revestimiento de $1 \mathrm{~m}^{2}$ de superficie (pared o suelo) de un edificio con gres/azulejo durante 50 años considerando un uso residencial, comercial o sanitario".

En este estudio se han analizado los comportamientos ambientales de tres tipos de baldosas considerando dos coloraciones del soporte distintas. Para el revestimiento de paredes, se ha considerado el azulejo de coloración blanca $(A B)$ y roja $(A R)$, agrupado como Azulejo medio. Para el pavimento, se han considerado el Gres Porcelánico medio (GP), el Gres Esmaltado de coloración blanca (GEB) y roja (GER) agrupado como Gres Esmaltado medio. Esta clasificación se basa en la contemplada por la Guía de la Baldosa Cerámica (9) y en las especificaciones de la UNE EN 14411 (10) de baldosas cerámicas. Asimismo, también es importante que se definan claramente los límites del sistema a analizar que determinan qué es lo que se incluye dentro del sistema estudiado y qué es lo que queda fuera. Normalmente, se excluyen del estudio aquellas etapas que se prevé que no serán significativas (11). En este estudio se han analizado todas las etapas del ciclo de vida de todas las baldosas cerámicas estudiadas, distinguiendo 4 fases principales tal y como se muestra en la siguiente figura 2 . 


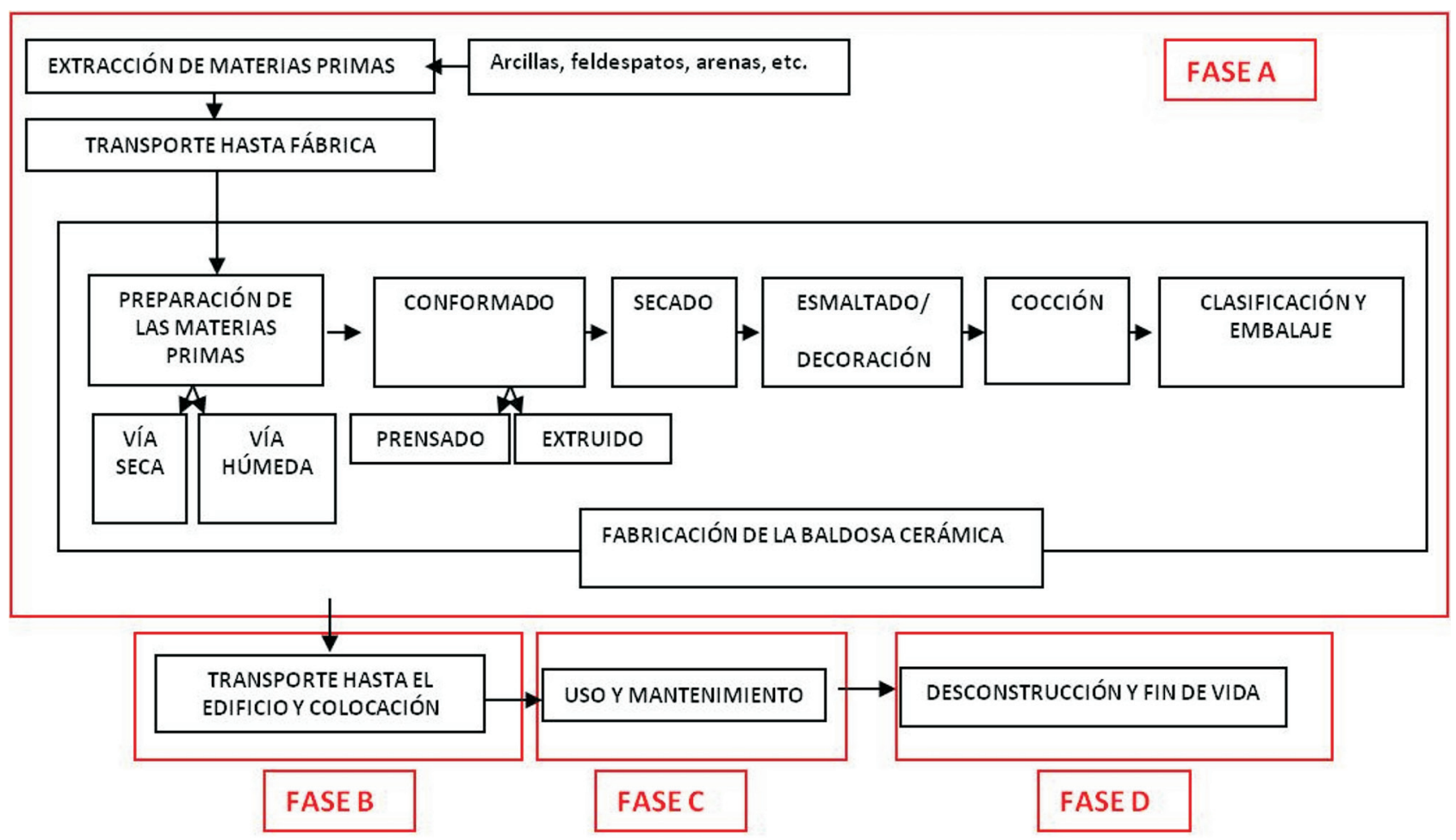

Fuente: ITC y ASCER, 2008

Los elementos que quedan fuera del sistema analizado son:

- La producción de maquinaria y equipamiento industrial debido a la dificultad que supone inventariar todos los bienes implicados y también porque la comunidad de ACV considera que el impacto ambiental por unidad de producto es bajo (ya que son asignados a una larga escala temporal debido a la duración de su vida útil y su utilización en otros procesos) en relación al resto de procesos que sí se incluyen.

- El reciclaje de los distintos residuos producidos a lo largo del ciclo de vida de las baldosas cerámicas debido al método de asignación de cargas aplicado.

De la misma manera, se han considerado como despreciables los impactos generados por aquellas materias primas que componen la baldosa cuyo peso sea inferior al $1 \%$ sobre el peso total de la baldosa.

\subsection{Análisis de inventario}

El inventario recoge las entradas y salidas de cada uno de los procesos que se incluyen en los límites del sistema estudiado. Los datos de inventario se han obtenido a partir de datos agregados de procesos en algunos casos y datos de procesos unitarios en otros, según la disponibilidad de datos en las empresas. Al tratarse de un análisis a nivel sectorial, los datos utilizados para el análisis son prome- dios ponderados en función de la producción, establecidas entre un número representativo de fabricantes del sector, no pudiendo atribuir, por tanto, los datos y los resultados a un único fabricante. La recogida de datos se ha realizado mediante cuestionarios compilando datos sobre consumos y, orígenes de las materias primas y energía utilizadas (energía térmica o electricidad), consumos de agua, materiales de embalaje, medios y distancias de transporte de la pieza finalizada, residuos producidos y emisiones directas producidas en la fábrica.

Los cuestionarios han sido distribuidos entre las empresas asociadas a ASCER, tanto de ciclo completo (producción de baldosas a partir de materias primas), ciclo parcial (fabricación de baldosas cerámicas a partir de la compra de gránulo atomizado), así como de empresas atomizadoras que únicamente producen gránulo atomizado. Del total de las empresas adheridas a ASCER, 56 empresas contestaron y completaron el cuestionario, representando más del $50 \%$ de la producción total de baldosas cerámicas en España. Para ello y con el objeto de asegurar la consistencia de los datos, se realizaron visitas a las empresas para verificar y completar "in situ" la información del cuestionario.

Los datos de inventario se presentan agregados por tipología de baldosa, diferenciando entre los tres grupos principales: gres porcelánico medio, gres esmaltado medio y azulejo medio. 
Fase A-Extracción de materias primas y fabricación

Para la fase de fabricación se han recopilado los datos medios de las materias primas que componen las baldosas, tal como se recoge en la tabla 1. Esta información se ha obtenido para cada tipo de baldosa a partir de los cuestionarios.

Además, para cada tipo de baldosa se han determinado los consumos de agua, de energía y las emisiones atmosféricas a lo largo de todo su proceso de fabricación, tal y como se recoge en la tabla 2.

Respecto a los materiales que entran en planta, se ha tenido en cuenta el tipo de transporte utilizado y la distancia media recorrida, ya que tienen distintos orígenes: provinciales, nacionales, europeos y otros.

Respecto al consumo energético en la fase de fabricación, la energía térmica procede únicamente del gas natural, utilizado en las etapas de secado por atomización, secado de las piezas conformadas y cocción. Una parte de las empresas encuestadas disponen de sistemas de cogeneración en la etapa de preparación de las materias primas donde se genera, además de energía térmica, una cantidad de electricidad que es vendida al gestor de energía eléctrica, considerándose ésta como una carga evitada en el sistema. Por otra parte, para obtener datos reales de las emisiones atmosféricas directas, se han realizado campañas de medidas experimentales en diferentes etapas del proceso productivo y para aquellas donde no ha sido posible, se han tomado datos de referencias bibliográficas (12-14).

El modelo que se ha empleado para este estudio permite también el cálculo de las emisiones no directas, es decir, aquellas no identificables por el productor y que pueden tener origen en la fabricación de determinadas materias primas o en la producción de energía primaria o transporte.

Los principales residuos generados en el proceso de fabricación de baldosas cerámicas corresponden a lodos con contenidos cerámicos, aguas residuales, residuos de producto cocido y sin cocer y los residuos de los embalajes. Excepto éstos últimos, el resto son casi enteramente reintroducidos en la fase de producción de la baldosa o son excluidos por formar parte de las operaciones de mantenimiento de las instalaciones, tal y como se indica en el apartado 2.2. Los vertidos de aguas residuales, se han desestimado ya que una práctica habitual es su reintroducción directa en la etapa de preparación de las materias primas o bien su reciclado como agente de limpieza de las plantas tras someterlas a un tratamiento físico-químico.
Tabla 1

Información recogida para el inventario en la etapa de fabricación

\begin{tabular}{|c|c|c|}
\hline \multicolumn{3}{|l|}{ ENTRADAS } \\
\hline \multirow{11}{*}{ Materias primas baldosa } & \multicolumn{2}{|l|}{ Arcilla } \\
\hline & \multicolumn{2}{|l|}{ Feldespatos } \\
\hline & \multicolumn{2}{|l|}{ Caolines } \\
\hline & \multicolumn{2}{|l|}{ Carbonatos } \\
\hline & \multicolumn{2}{|c|}{ Silicatos } \\
\hline & \multicolumn{2}{|c|}{ Material recuperado durante el proceso } \\
\hline & \multirow{4}{*}{ Esmalte genérico } & Arcillas \\
\hline & & Feldespatos \\
\hline & & Cuarzo \\
\hline & & Otros \\
\hline & \multicolumn{2}{|l|}{ Pigmentos } \\
\hline
\end{tabular}

Tabla 2

Datos medios de inventario para cada tipo de baldosa

\begin{tabular}{|c|c|c|c|c|}
\hline \multicolumn{2}{|l|}{ ENTRADAS } & $\begin{array}{l}\text { Gres } \\
\text { Porcelánico } \\
\text { medio }\end{array}$ & $\begin{array}{c}\text { Gres } \\
\text { esmaltado } \\
\text { medio }\end{array}$ & $\begin{array}{l}\text { Azulejo } \\
\text { medio }\end{array}$ \\
\hline \multirow{3}{*}{$\begin{array}{l}\text { Agua } \\
{\left[\mathrm{kg} / \mathrm{m}^{2}\right]}\end{array}$} & Agua de pozo & $9,6 \mathrm{E}+00$ & $9,6 \mathrm{E}+00$ & $9,6 \mathrm{E}+00$ \\
\hline & Agua red & $1,7 \mathrm{E}+00$ & $1,7 \mathrm{E}+00$ & $1,7 \mathrm{E}+00$ \\
\hline & Agua recuperada & $5,0 \mathrm{E}+00$ & $5,0 \mathrm{E}+00$ & $5,0 \mathrm{E}+00$ \\
\hline \multirow{3}{*}{$\begin{array}{l}\text { Energía } \\
{\left[\mathrm{MJ} / \mathrm{m}^{2}\right]}\end{array}$} & $\begin{array}{l}\text { Energía térmica } \\
\text { atomizador }\end{array}$ & $4,6 \mathrm{E}+01$ & $4,6 \mathrm{E}+01$ & $4,6 \mathrm{E}+01$ \\
\hline & $\begin{array}{l}\text { Energía térmica } \\
\text { secadores }\end{array}$ & $8,9 \mathrm{E}+00$ & $8,9 \mathrm{E}+00$ & $8,9 \mathrm{E}+00$ \\
\hline & $\begin{array}{l}\text { Energía térmica } \\
\text { hornos }\end{array}$ & $6,7 \mathrm{E}+01$ & $6,3 \mathrm{E}+01$ & $5,8 \mathrm{E}+01$ \\
\hline \multicolumn{5}{|l|}{ SALIDAS } \\
\hline \multicolumn{2}{|c|}{ Baldosa acabada $\left[\mathrm{kg} / \mathrm{m}^{2}\right]$} & 22,6 & 20,7 & 17,7 \\
\hline \multirow{6}{*}{$\begin{array}{l}\text { Emisiones atomos- } \\
\text { féricas }\left(^{*}\right)\left[\mathrm{kg} / \mathrm{m}^{2}\right]\end{array}$} & $\mathrm{CO}_{2}$ & 8,0 E-01 & $1,1 \mathrm{E}+00$ & $1,7 \mathrm{E}+00$ \\
\hline & $\mathrm{HCl}$ & 4,2 E-03 & 3,8 E-03 & 3,6 E-03 \\
\hline & \begin{tabular}{|l|} 
Partículas \\
\end{tabular} & $6,5 \mathrm{E}-03$ & 5,9 E-03 & 5,1 E-03 \\
\hline & $\mathrm{SO}^{2}$ & $14,9 \mathrm{E}-03$ & $11,2 \mathrm{E}-03$ & 9,5 E-03 \\
\hline & $\mathrm{HF}$ & $2,5 \mathrm{E}-03$ & 2,3 E-03 & 1,9 E-03 \\
\hline & $\mathrm{Pb}$ & 9,7 E-06 & 8,9 E-06 & 7,6 E-06 \\
\hline
\end{tabular}

(*) Estas emisiones no incluyen las debidas a los procesos de combustión para la obtención de energía térmica para el atomizador, secaderos y hornos.

\section{Fase B-Transporte y colocación del producto acabado}

El sector cerámico produce baldosas que son comercializadas en todo el mundo. La tabla 3 muestra el tipo de transporte y el destino principal de las baldosas según las estadísticas realizadas por ASCER durante 2008.

La colocación de las baldosas se hace de modo manual y se ha considerado que se utiliza mortero adhesivo para su fijación (9). Es en esta fase donde se generan residuos de los materiales de embalaje, cuya gestión es responsabilidad del cliente que recibe la mercancía. 
Tabla 3

Destinos y medios de transporte más habitual para cada tipo de baldosa

\begin{tabular}{|l|c|c|c|}
\hline Destino & $\begin{array}{c}\text { Tipo } \\
\text { de transporte }\end{array}$ & $\begin{array}{c}\text { Porcentaje medio sobre } \\
\text { la producción de baldosas } \\
\text { cerámicas (\%) }\end{array}$ & $\begin{array}{c}\text { Distancia } \\
\text { media } \\
(\mathbf{k m})\end{array}$ \\
\hline España & Camión 27t & 50 & 500 \\
\hline Europa & Camión 27t & 30 & 2.000 \\
\hline $\begin{array}{l}\text { Resto del } \\
\text { mundo }\end{array}$ & $\begin{array}{c}\text { Carguero } \\
\text { transoceánico }\end{array}$ & 20 & 5.000 \\
\hline
\end{tabular}

Con el objeto de definir los posibles escenarios de gestión de estos residuos se deben aplicar las normativas y estadísticas representadas en el escenario del receptor. Para ello, se han utilizado los siguientes modelos con tres escenarios diferentes: gestión de residuos en España, en Europa y resto del Mundo utilizando los datos medios de recogida selectiva de los diferentes tipos de residuos. (15) (tabla 4).

La colocación tiene lugar de manera manual. De acuerdo con los datos obtenidos y con

Tabla 4

Gestión de los residuos de embalaje según área geográfica de destino

\begin{tabular}{|l|c|c|c|}
\hline \multicolumn{1}{|c|}{ Tipo de gestión de residuos } & España & Europa & Mundo \\
\hline Cartón a incineración & $20 \%$ & $2 \%$ & $20 \%$ \\
\hline Cartón a vertedero & $10 \%$ & $24 \%$ & $10 \%$ \\
\hline Cartón a reciclaje & $70 \%$ & $74 \%$ & $20 \%$ \\
\hline Película de polietileno a incineración & $14 \%$ & $26 \%$ & $10 \%$ \\
\hline Película de polietileno a vertedero & $66 \%$ & $47 \%$ & $70 \%$ \\
\hline Película de polietileno a reciclaje & $20 \%$ & $27 \%$ & $70 \%$ \\
\hline Palé de madera a incineración & $47 \%$ & $20 \%$ & $20 \%$ \\
\hline Palé a vertedero & $9 \%$ & $42 \%$ & $50 \%$ \\
\hline Palé a reciclaje & $44 \%$ & $38 \%$ & $30 \%$ \\
\hline
\end{tabular}

Tabla 5

Escenarios de mantenimiento y limpieza

\begin{tabular}{|l|c|c|c|}
\hline Material limpieza & $\begin{array}{c}\text { Uso } \\
\text { residencial }\end{array}$ & $\begin{array}{c}\text { Uso } \\
\text { comercial }\end{array}$ & $\begin{array}{c}\text { Uso } \\
\text { sanitario }\end{array}$ \\
\hline Agua por lavado $\left(\mathrm{kg} / \mathrm{m}^{2}\right)$ & 0,1 & 0,1 & 0,1 \\
\hline Detergente por lavado $\left(\mathrm{kg} / \mathrm{m}^{2}\right)$ & 0,0006 & 0,0006 & 0,0006 \\
\hline $\begin{array}{l}\text { Frecuencia de lavado (número de } \\
\text { veces/semana) }\end{array}$ & 1 & 7 & 14 \\
\hline $\begin{array}{l}\text { Vida media estimada de la baldosa } \\
\text { (años)* }\end{array}$ & 50 & 50 & 50 \\
\hline
\end{tabular}

* Se ha estimado igual que la vida útil del edificio según UNE EN 14411: 2004 Baldosas cerámicas. Definiciones, clasificación, características y marcado.

el fin de aplicar un escenario real, se ha establecido que para la instalación se requiere la aplicación de mortero rápido $\left(\mathrm{CaSO}_{4}\right)(9)$. Los morteros cola son adhesivos cementosos formados por una mezcla de conglomerantes hidráulicos, cargas minerales y aditivos orgánicos, que sólo tienen que mezclarse con agua o adición líquida justo antes de su uso. Están formados por una mezcla de cemento blanco o gris, cargas minerales de naturaleza silícea y/o caliza y aditivos orgánicos: retenedores de agua, polímeros redispersables en agua, modificadores reológicos, fibras, etc. La cantidad de mortero adhesivo depende del tipo de baldosa, y oscila entre los 1,5 kg por $\mathrm{m}^{2}$ de azulejo, hasta los 3,5 $\mathrm{kg}$ por $\mathrm{m}^{2}$ de gres a instalar (9). Además se ha considerado el agua necesaria para formar la pasta adhesiva, cuya proporción es de 1:4.

\section{Fase C- Uso}

La fase de uso comprende todas aquellas actividades que tiene lugar una vez la baldosa ha sido instalada y hasta su desinstalación. Para este producto, dichas actividades pueden reducirse a la limpieza higiénica, ya que la utilización de baldosas no requiere de otra actividad de mantenimiento ni reemplazo durante el arco temporal establecido de 50 años de vida útil $(9,10)$. Por lo tanto, se ha considerado la limpieza de las baldosas utilizando agua y detergente líquido. Asimismo se ha supuesto una determinada frecuencia de limpieza a lo largo de su vida útil que depende del uso que se hace de las baldosas y de los hábitos de cada persona, pudiendo simplificarse en estos tres escenarios (véase Tabla 5). Los datos representan los consumos de agua y detergente por lavado y por $\mathrm{m}^{2}$ de baldosa, dichos escenarios siguen las premisas planteadas por Paulsen, J. (16).

\section{Fase D- Demolición y fin de vida}

Esta fase final considera la demolición y posterior gestión de los residuos sólidos generados, como el final de la vida útil de la baldosa cerámica. Teniendo en cuenta que las baldosas representan un $0,32 \%$ sobre el peso total del edificio [Datos ITeC: Institut de Tecnologia de Construcció de Catalunya], el consumo energético asociado a su desmantelamiento puede ser, por lo tanto desestimado. Sin embargo, una vez demolido el edificio, se ha supuesto que las baldosas son depositadas en un $83 \%$ vertederos como material de construcción inerte (mientras que el $17 \%$ restante son revalorizados al ser reutilizados como material de relleno para obras de pavimentación o similares), tal y como se indican en el informe del Plan Nacional Integrado de Residuos. Por este motivo se han analizado los impactos ambientales de este tipo de gestión y aquellos asociados al transporte del material de demolición hasta el vertedero, estimándose una distancia media de $50 \mathrm{~km}$ entre el edificio y el vertedero.

\subsection{Evaluación de impactos e interpretación}

Las categorías de impacto ambiental escogidas para la evaluación de Impactos son las mostradas en la tabla 6. Estas categorías son 
las recomendadas en la prEN15804 (17) sobre Declaraciones Ambientales de Producto de la construcción. Además de estas categorías, en la evaluación de impactos se han incluido una serie de indicadores de flujo para ayudar a la toma de decisiones y la interpretación de resultados. Estos indicadores son:

- consumo de energía primaria: cantidad total de energía calorífica bruta consumida por el sistema, procedente tanto de recursos renovables como no renovables, teniendo en cuenta tanto los consumos directos para la fabricación del producto, como los indirectos derivados de las actividades para la obtención de la energía directa. Unidad de medida: Mega Joules (MJ).

- consumo de agua: cantidad total de agua dulce consumida por el sistema. Se calcula sumando la cantidad de todos los consumos de agua que se producen a lo largo del ciclo de vida del producto. Unidad de medida: kilogramos (kg).

En la tabla 7 se muestran los valores obtenidos de las categorías de impacto para cada tipo de baldosa.

En las Figuras (3, 4 y 5$)$ se puede observar la contribución de cada fase del ciclo de vida al valor total de cada una de las categorías de impacto evaluadas.

Como se puede observar, las fases que más influyen en los indicadores ambientales (energía y agua) son las de fabricación y uso. Cabe destacar que los impactos generados en la fase de uso son derivados exclusivamente de la actividad de limpieza, actividad que depende altamente de los hábitos del usuario final de la baldosa y del escenario en el que se encuentre, por lo que puede ser un dato subjetivo. De hecho, la actividad de limpieza es aplicable cualquier tipo de recubrimiento, sea cual sea el material. Sin embargo, dada la elevada durabilidad de las baldosas, en el arco temporal considerado, no se ha considerado la necesidad de sustituirlas, a diferencia de lo que puede ocurrir con materiales alternativos. En estudios futuros, no obstante, se podrán establecer distintos escenarios en función de los tipos de servicios en la vida útil que se presentan en Paulsen J. (16).

Además, los autores han aplicado algunas hipótesis con influencia en los cálculos de los flujos de referencia relativas al peso de las baldosas y al consumo energético durante la producción de las mismas. Se ha analizado la influencia en la variación de estas hipótesis en los resultados globales mediante un análisis de sensibilidad.

\section{Tabla 6}

Indicadores de impacto utilizados

\begin{tabular}{|c|c|}
\hline Categoría de impacto & Agotamiento de Recursos Abióticos (ADP) \\
\hline Resultado del inventario: & Extracción de minerales y combustibles fósiles (en $\mathrm{kg}$ ) \\
\hline $\begin{array}{l}\text { Factor de caracterización y } \\
\text { unidades del indicador }\end{array}$ & $\begin{array}{l}\text { Potencial de agotamiento para cada extracción de } \\
\text { minerales y combustibles fósiles (kg de Sb equiva- } \\
\text { lente/kg extraídos) }\end{array}$ \\
\hline Categoría de impacto & Acidificación (AP) \\
\hline Resultado del inventario: & Emisiones de substancias acidificantes (en kg) \\
\hline $\begin{array}{l}\text { Factor de caracterización } \\
\text { unidades del indicador }\end{array}$ & $\begin{array}{l}\text { potencial de acidificaci } \\
\text { de } \mathrm{SO}_{2} \text { equivalente/kg }\end{array}$ \\
\hline Categoría de impacto & Calentamiento Global (GWP) \\
\hline Resultado del inventario: & $\begin{array}{l}\text { Emisiones atmosféricas de gases de efecto inverna- } \\
\text { dero (en } \mathrm{kg} \text { ) }\end{array}$ \\
\hline $\begin{array}{l}\text { Factor de caracterización y } \\
\text { unidades del indicador }\end{array}$ & $\begin{array}{l}\text { Potencial de calentamiento global de cada gas de } \\
\text { efecto invernadero en un horizonte temporal de } \\
100 \text { años (kg de } \mathrm{CO}_{2} \text { equivalente/kg de gas de efecto } \\
\text { invernadero) }\end{array}$ \\
\hline Categoría de impacto & Formación de foto-oxidantes (POPC) \\
\hline Resultado del inventario: & Emisiones de substancias (VOC, $\mathrm{CO}$ ) al aire (en $\mathrm{kg}$ ) \\
\hline $\begin{array}{l}\text { Factor de caracter } \\
\text { unidades del indica }\end{array}$ & $\begin{array}{l}\text { Potencial de creación de ozono fotoquímico de cada } \\
\text { emisión de VOC o CO al aire (kg de etileno equiva- } \\
\text { lente/kg de emisión foto-oxidante) }\end{array}$ \\
\hline
\end{tabular}

\begin{tabular}{|l|l|}
\hline \multicolumn{1}{|c|}{ Categoría de impacto } & \multicolumn{1}{c|}{$\begin{array}{c}\text { Potencial de agotamiento del ozono } \\
\text { estratosférico (ODP) }\end{array}$} \\
\hline Resultado del inventario: & Emisiones de sustancias al aire (en kg) \\
\hline $\begin{array}{l}\text { Factor de caracterización y y y } \\
\text { unidades del indicador }\end{array}$ & $\begin{array}{l}\text { Potencial de agotamiento de cada emisión en el aire } \\
\text { (kg de R11 equivalente/kg de emisión) }\end{array}$ \\
\hline \multicolumn{1}{|c|}{ Categoría de impacto } & \multicolumn{1}{c|}{ Eutrofización (EP) } \\
\hline Resultado del inventario: & Emisiones de nutrientes al aire, agua o suelo (en kg) \\
\hline Factor de caracterización y & $\begin{array}{l}\text { Potencial de eutrofización de cada emisión eutrofi- } \\
\text { zante en el aire, agua o suelo (kg de } \mathrm{PO}_{4}{ }^{3-} \text { equivalente/ } \\
\text { kg de emisión eutrofizante) }\end{array}$ \\
\hline unidades del indicador &
\end{tabular}

Tabla 7

Perfil ambiental para cada tipo de baldosas (unidades $/ \mathrm{m}^{2}$ )

\begin{tabular}{|l|c|c|c|c|}
\hline \multicolumn{1}{|c|}{ Tipología } & Unidades & $\begin{array}{c}\text { Gres } \\
\text { Porcelánico } \\
\text { medio }\end{array}$ & $\begin{array}{c}\text { Gres } \\
\text { esmaltado } \\
\text { medio }\end{array}$ & $\begin{array}{c}\text { Azulejo } \\
\text { medio }\end{array}$ \\
\hline $\begin{array}{l}\text { Agotamiento de Recursos } \\
\text { Abióticos }\end{array}$ & $\mathrm{kg} \mathrm{de} \mathrm{Sb} \mathrm{eq.}$ & $1,1 \mathrm{E}-01$ & $1,0 \mathrm{E}-01$ & $1,0 \mathrm{E}-01$ \\
\hline Potencial de Acidificación & $\mathrm{kg} \mathrm{de} \mathrm{\textrm {SO } _ { 2 } \text { eq. }}$ & $7,9 \mathrm{E}-02$ & $7,0 \mathrm{E}-02$ & $6,8 \mathrm{E}-02$ \\
\hline Potencial de Eutrofización & $\mathrm{kg} \mathrm{de} \mathrm{\textrm {PO } _ { 4 } { } ^ { 3 - } \text { eq. }}$ & $9,6 \mathrm{E}-03$ & $9,1 \mathrm{E}-03$ & $8,9 \mathrm{E}-03$ \\
\hline $\begin{array}{l}\text { Potencial de Calentamiento } \\
\text { Global }\end{array}$ & $\mathrm{kg} \mathrm{de} \mathrm{\textrm {CO } _ { 2 } \text { eq. }}$ & $1,8 \mathrm{E}+01$ & $1,7 \mathrm{E}+01$ & $1,9 \mathrm{E}+01$ \\
\hline $\begin{array}{l}\text { Potencial de Agotamiento } \\
\text { de Ozono Estratosferico }\end{array}$ & $\mathrm{kg} \mathrm{de} \mathrm{R11} \mathrm{eq.}^{\text {Potencial de Formación de }}$ & $2,1 \mathrm{E}-07$ & $1,7 \mathrm{E}-07$ & $1,8 \mathrm{E}-07$ \\
\hline $\begin{array}{l}\text { Ozono fotoquímico } \\
\text { Consumo de Energía }\end{array}$ & $\mathrm{MJ} \mathrm{H}_{4}$ eq. & $2,0 \mathrm{E}-02$ & $2,0 \mathrm{E}-02$ & $1,9 \mathrm{E}-02$ \\
\hline $\begin{array}{l}\text { Primaria } \\
\text { Consumo de Agua }\end{array}$ & $3,0 \mathrm{E}+02$ & $2,9 \mathrm{E}+02$ & $3,0 \mathrm{E}+02$ \\
\hline
\end{tabular}



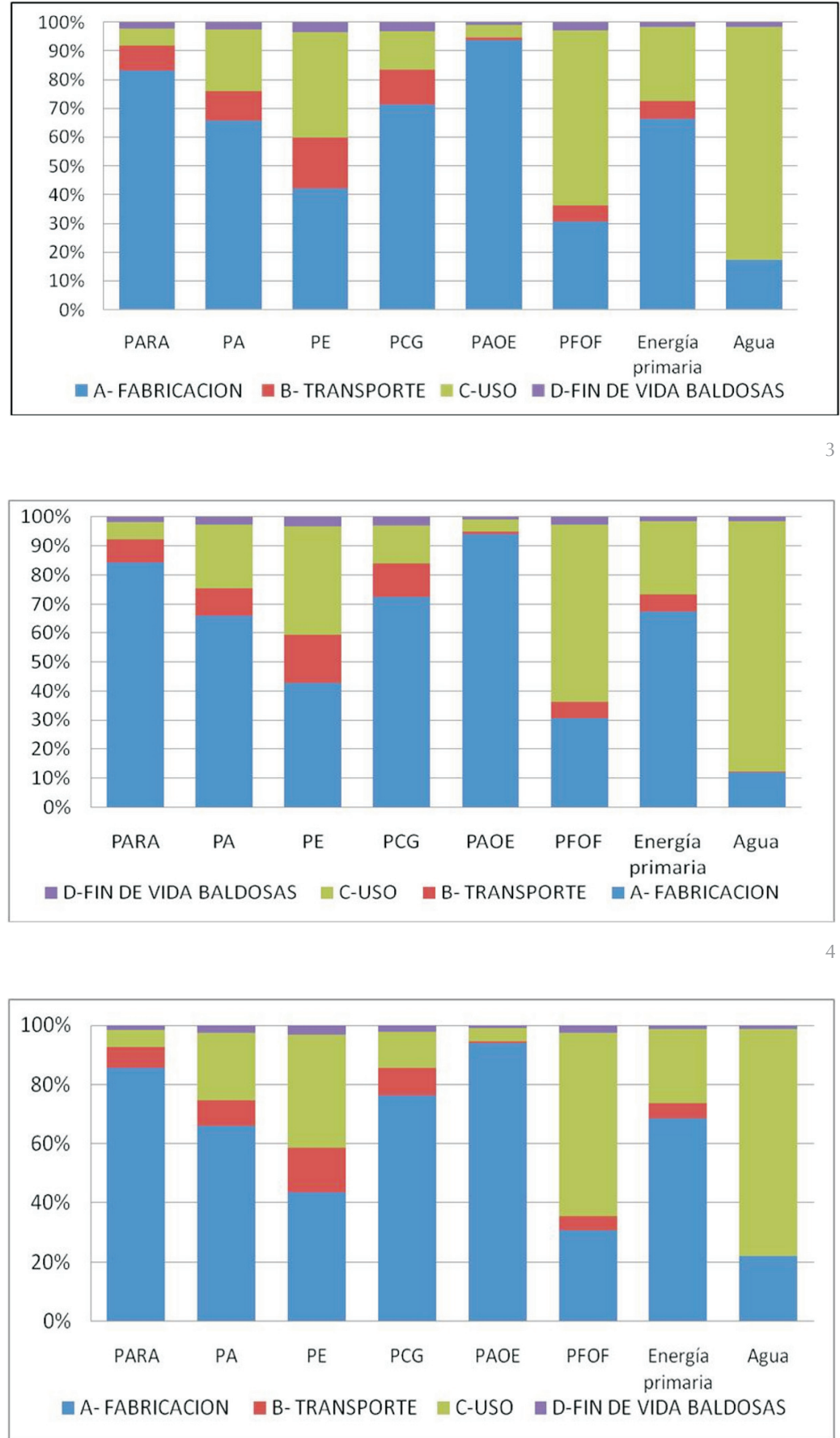

3. Contribuciones de las fases de ciclo de vida a las categorías de impacto para el Gres Porcelánico medio.

4. Contribuciones de las fases de ciclo de vida a las categorías de impacto para el Gres Esmaltado medio.

5. Contribuciones de las fases de ciclo de vida a las categorías de impacto para el Azulejo medio.

6. Variación del indicador PCG al reducir los consumos energéticos en un $20 \%$
Este tipo de análisis demuestra la importancia de utilizar datos representativos, así como de los efectos potenciales generados por cambios en los procesos productivos. La Figura 6 muestra el resultado de uno de estos análisis, concretamente, la reducción del $20 \%$ en el consumo energético directo durante la fabricación de las piezas y su efecto en la categoría de impacto de Potencial de Calentamiento Global.

La cifra de reducción de consumo energético considerada se basa en las acciones europeas recogidas en "Acción de la UE contra el cambio climático- A la cabeza de la respuesta mundial hasta el 2020 y más allá" de cara al cumplimiento del protocolo de Kioto, y a la espera de una nueva resolución que pueda surgir de la cumbre de Copenhague de diciembre de 2009. En este plan, los líderes europeos asumieron el compromiso de transformar Europa en una economía de alta eficiencia energética y baja emisión de carbono. Además, subrayaron su determinación de que la Unión Europea sea la primera en tomar la iniciativa, asumiendo el compromiso de reducir las emisiones en al menos un $20 \%$ con respecto a los niveles de 1990 para el año 2020, independientemente de las acciones emprendidas por los demás países. En este escenario debe considerarse como hipotético ya que su aplicación real en la industria puede resultar a día de hoy poco factible puesto que se trata de un sector con un consumo energético muy optimizado y elevada implantación de Mejores Técnicas Disponibles. Sin embargo se ha considerado interesante poder analizarlo para averiguar concretamente su influencia sobre el valor de la categoría de impacto de calentamiento global (PCG).

Como se observa en la figura 4, la reducción de las emisiones de $\mathrm{CO}_{2}$ equivalente, en todo el total del ciclo de vida de la baldosa es de un $12 \%$, es decir, se evitaría la emisión de más de $2,1 \mathrm{~kg}$ de $\mathrm{CO}_{2} \mathrm{eq} / \mathrm{m}^{2}$. Teniendo en cuenta que la producción de baldosas es de casi 500 millones de metros cuadrados al año, esto implicaría una reducción de más de 1 millón de toneladas de $\mathrm{CO}_{2}$ eq al año.

A la vista de estos resultados se plantea como una línea de estudio muy interesante, el identificar las posibilidades reales de reducción del consumo energético para dicho sector, ya que en los últimos años el esfuerzo que se ha realizado en materia de eficiencia energética ha sido muy alto y la propuesta de la UE es poco factible para este sector.

\section{REDACCIÓN DE LAS REGLAS DE CATEGORÍA DE PRODUCTO PARA MATERIALES DE RECUBRIMIENTO CERÁMICOS}

Uno de los objetivos del estudio de ACV de la baldosa cerámica a nivel sectorial era el tener 
la información de partida para la redacción de las Reglas de Categoría de Producto (RCP) para este tipo de recubrimiento. Las RCP son un conjunto de directrices que guían en la redacción de las DAP y en la realización del estudio de ACV que las sustenta. Entre otras cosas, las RCP determinan cuál debe ser la unidad funcional aplicada, las categorías de impacto evaluadas, los límites del sistema estudiado o los requisitos de calidad de los datos utilizados.

Las Declaraciones Ambientales de Producto (también Ilamadas EPD (Environmental Product Declarations) o ecoetiquetas tipo III según la clasificación ISO, facilitan la comunicación objetiva, comparable y creíble del comportamiento ambiental de los productos. Las DAP no ofrecen criterios sobre la preferencia ambiental de un producto ni establecen unos requisitos mínimos a cumplir. No obstante, el hecho de estudiar un producto en profundidad siempre lleva a la detección de alternativas de mejora. Generalmente, la información contenida en una DAP ha sido verificada por una tercera parte independiente $y$, consiste en datos relevantes sobre los impactos ambientales generados por un producto a lo largo de su ciclo de vida (categorías de impacto y consumo de materias primas y producción de emisiones y residuos relevantes). Para que las DAP realizadas por distintos fabricantes sean coherentes entre sí es fundamental que sigan las mismas directrices sobre cómo aplicar la metodología del ACV (véase Figura 7).

En la redacción del borrador de las RCP para materiales de recubrimiento cerámico se han seguido las normas UNE EN ISO 14025 (5) e ISO 21930 (6) y el borrador prEN 15804 (17), además se han consultado las RCP desarrolladas en otros sistemas, en particular en el sistema de RCP para la preparación de EPD de Environdec (Swedish Environmental Management Council).

Una vez elaborado el primer borrador de las RCP, se sometió a exposición pública a empresas y organizaciones del sector para que presentaran sus comentarios y opiniones sobre los contenidos de las mismas, asegurando así la participación de las diferentes partes interesadas en el proceso de elaboración de las RCP.

La tabla 8, recoge los contenidos de las RCP de recubrimientos cerámicos.

Siguiendo los procedimientos del sistema DAPC, las RCP han sido revisadas por su consejo asesor (formado por profesionales independientes y expertos en ecoetiquetado, análisis de ciclo de vida y el sector de la construcción). Finalmente, el CAATEEB

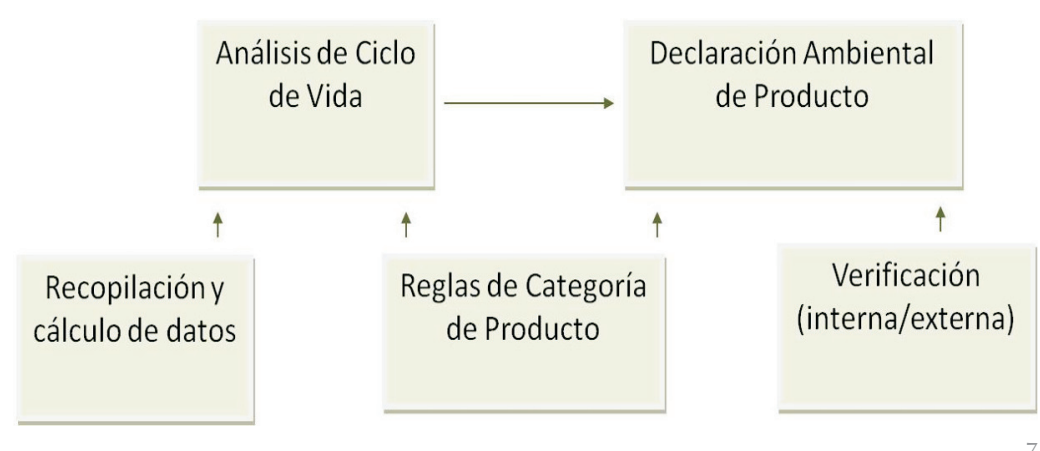

(administrador del sistema) ha procedido a su aprobación el día 11 de junio de 2010. Una vez aprobadas, las RCP de recubrimientos cerámicos están disponibles para su utilización por parte de cualquier empresa del sector que desee desarrollar una DAP en el sistema DAPC. Las RCP tienen una validez de 5 años, momento en el cuál se procederá a su revisión. Sin embargo, si se produjesen cambios significativos en el sistema de producción de las baldosas o en la metodología del ACV, el CAATEEB procederá a la revisión del documento antes de finalizar el período de validez.

En este sentido, se considera necesario indicar que los impulsores del sistema DAPC

Tabla 8

Contenidos de las RCP de recubrimientos cerámicos

\begin{tabular}{|c|c|}
\hline Apartado & Contenidos generales \\
\hline Introducción & $\begin{array}{l}\text { Descripción del objetivo, del proceso de desarrollo de } \\
\text { las RCP y de los períodos de validez de las RCP y las } \\
\text { DAP resultantes. }\end{array}$ \\
\hline Conceptos y definiciones & $\begin{array}{l}\text { Definiciones de los conceptos clave utilizados en el do- } \\
\text { cumento: categoría de producto, ciclo de vida, impacto } \\
\text { ambiental, proceso unitario, etc. }\end{array}$ \\
\hline $\begin{array}{l}\text { Definición de la categoría de } \\
\text { producto }\end{array}$ & $\begin{array}{l}\text { Definición clara de los requisitos que debe cumplir el } \\
\text { producto para entrar en la categoría de producto en } \\
\text { cuestión. }\end{array}$ \\
\hline $\begin{array}{l}\text { Etapas del ciclo de vida a } \\
\text { incluir }\end{array}$ & $\begin{array}{l}\text { Indicaciones sobre las etapas y procesos a incluir en los } \\
\text { límites del sistema de manera obligatoria o opcional. }\end{array}$ \\
\hline Reglas de cálculo del ACV & $\begin{array}{l}\text { Descripción de las reglas a considerar en la definición } \\
\text { de la unidad funcional, la vida útil de referencia del pro- } \\
\text { ducto, la inclusión de entradas y salidas, la descripción } \\
\text { de los datos, etc. }\end{array}$ \\
\hline Análisis de inventario & $\begin{array}{l}\text { Descripción de los métodos de recogida de datos, los } \\
\text { procedimientos de cálculo y de asignación de flujos de } \\
\text { entrada y de salida. }\end{array}$ \\
\hline Evaluación de impactos & $\begin{array}{l}\text { Categorías de impacto a considerar, unidades de medida } \\
\text { y métodos de evaluación de impactos a aplicar. }\end{array}$ \\
\hline Informe del proyecto & $\begin{array}{l}\text { Descripción de los contenidos que deberá tener el infor- } \\
\text { me del proyecto para su posterior verificación. }\end{array}$ \\
\hline Contenido de la DAP & Definición de los contenidos y formato de la DAP. \\
\hline Bibliografía & $\begin{array}{l}\text { Referencias bibliográficas utilizadas en la definición de } \\
\text { las RCP. }\end{array}$ \\
\hline
\end{tabular}


tienen la voluntad de que éste sea compatible con otros sistemas de ecoetiquetado tipo III, como por ejemplo el sistema internacional "Environmental Product Declaration" administrado por el International EPD Consortium (14).

Además, el sistema es totalmente compatible con el artículo 6.2. del Decreto 21/2006 de la Generalitat de Catalunya, por el cual se regula la adopción de criterios ambientales y de ecoeficiencia en los edificios, dado que las DAP resultantes serán etiquetas tipo III de acuerdo con la norma UNE ISO 14025. Por otro lado, cabe recordar que el Código Técnico de la Edificación (CTE), en su capítulo 2 (párrafo 5.2.4), hace referencia a la posibilidad de que las Administraciones Públicas competentes reconozcan las certificaciones medioambientales que consideren el análisis del ciclo de vida de los productos. La Orden VIV/1744/2008, por la que se regula el registro general del CTE, contempla en su apartado 2.2.c.3 la inscripción en el registro las certificaciones medioambientales del análisis del ciclo de vida de los productos y otras evaluaciones medioambientales de los edificios.

\section{CONCLUSIONES}

El sector de la baldosa cerámica está sufriendo directamente las consecuencias de la crisis económica global que ha afectado especialmente al sector de la construcción en España. En momentos como este, un estudio de este tipo, además de ser relevante, constituye una herramienta muy valiosa a la hora de afrontar las dificultades y detectar aquellos potenciales de mejora. Conocer las principales problemáticas de carácter ambiental relativas a la producción, distribución, uso y gestión del fin de vida asociadas a la baldosa cerámica es fundamental para desarrollar planes estratégicos de diferenciación e innovación del producto basados en la variable ambiental. La información que ha obtenido ASCER mediante el estudio a escala sectorial es explotable tanto a nivel industrial como a nivel de comunicación, pues además de identificar las variables susceptibles de mejora, también es útil para obtener argumentos científicos que apoyen sus campañas de comunicación sobre este sector industrial.

El ACV a escala sectorial ha permitido evaluar el impacto ambiental total y de cada una de las fases del ciclo de vida de los tipos de baldosas cerámicas mayoritarios, detectando aquellas fases y procesos que contribuyen en mayor medida en cada una de las categorías de impacto evaluados. Los resultados obtenidos muestran que, para todas las baldosas analizadas, la fase de fabricación es la que mayor impacto tiene.
Los resultados han determinado que la fase de fabricación es la que contribuye en mayor medida al impacto ambiental de este producto. Esto se debe mayoritariamente al consumo de gas natural en los procesos de cocción, secado por atomización y secado de las piezas conformadas, provocando una contribución del $71 \%$ sobre el indicador de Potencial de Calentamiento Global (PCG).

Valorando las posibles mejoras ambientales, se ha podido comprobar cómo el ahorro energético durante la fase de fabricación puede significar una reducción considerable en las emisiones de gases de invernadero.

Durante su fase de uso, la baldosa cerámica es un producto que no requiere consumos energéticos para su correcto funcionamiento, y su vida útil puede ser equivalente a la del edificio mismo. La única operación de mantenimiento para este tipo de recubrimiento es la de limpieza. Cabe destacar que la actividad de limpieza, convenientemente especificada, es aplicable a otros tipos de materiales utilizados como recubrimiento. Para esta operación, se ha identificado cómo las diferentes opciones y frecuencia de lavado influyen en los consumos de agua y detergente. De hecho, el tipo de limpieza en función del lugar de aplicación de las baldosas (residencial, comercial y sanitaria) influye considerablemente los potenciales de eutrofización, destrucción de recursos abióticos y consumo de energía primaria. Aumentar la frecuencia de lavado significa aumentar proporcionalmente estos impactos. También cabe destacar la fase de transporte de las baldosas hasta el lugar de destino debido a su impacto significativo, aunque es claramente inferior a las fases de fabricación y uso. Se ha podido comprobar que en el caso de largas distancias y para transportar la misma cantidad de producto, el transporte terrestre tiene un impacto ambiental mayor que el marítimo.

El esfuerzo de investigación y recopilación de datos de inventario realizado para este ACV ha sido sumamente útil a la hora de redactar las Reglas de Categoría de Producto para los revestimientos cerámicos. Con las RCP ya aprobadas, los fabricantes de baldosas cerámicas tras realizar un ACV de sus productos siguiendo las directrices contenidas en las RCP pueden obtener una Declaración Ambiental de Producto, que deberá ser verificada y registrada adecuadamente. Estas DAP podrán ser utilizadas tanto por el fabricante para conocer mejor su sistema productivo y poder optimizarlo y también como herramienta de marketing y comunicación ambiental, útil para ser utilizada como criterio de compra. 


\section{AGRADFCIMIENTOS}

El proyecto ha sido realizado para ASCER mediante el apoyo financiero del IMPIVA (Instituto de la Mediana y Pequeña
Industria Valenciana de la Generalitat Valenciana) y los Fondos FEDER, a través de los Planes Sectoriales de Competitividad con número de expediente IMPCNC/2008/124.

\section{BIBLIOGRAFÍA}

(1) Argüello Méndez, T.; Cuchí Burgos, A.: "Análisis del impacto ambiental asociado a los materiales de construcción empleados en las viviendas de bajo coste del programa 10×10 con Techo-Chiapas del CYTED", Informes de la Construcción, Vol. 60, n 509 (2008), pp. 25-34.

(2) UNE-EN ISO 14040:2006 Gestión ambiental. Análisis de ciclo de vida. Principios y marco de referencia (ISO 14040:2006).

(3) UNE-EN ISO 14044:2006 Gestión ambiental. Análisis de ciclo de vida. Requisitos y directrices (ISO 14044:2006).

(4) RCP, 2010. Reglas de Categoría de Producto (RCP) para productos de recubrimiento cerámico RCP 002 Versión 1 (2010).

(5) UNE-ISO 14025:2007 Etiquetas y declaraciones ambientales. Declaraciones ambientales tipo III. Principios y procedimientos (ISO 14025:2006).

(6) ISO 21930:2007 Sustainability in building construction - Environmental declaration of building products.

(7) Fullana P.; Gazulla, C.; Bala, A.; Chiva, P.; Fabregó, L.; Vidal, M.: "Guía de Aplicación Ecojoguina. Generalitat de Catalunya". Barcelona (ISBN 9788439378914), (2009) pp. 41-42.

(8) Fullana, P.; Puig, R.: "Análisis del Ciclo deVida". Ed. Rubes, Barcelona (ISBN 8449700701), (1997) pp. 12-14.

(9) González, M.; Miralles, A. (ASCER); Monfort, R.; Montón, L.; Castaño, J.R. (COACV); Mazarredo, F.C.; Palencia, J.J. (CIT); García, A.; Enrique, J.E.; Silva, G. (ITC); Benedé, R. (ANFAPA); García, M. (CEMARKSA); Pla, F.; Pascual, J. (IVE):"Guía de la baldosa cerámica Valencia": Instituto Valenciano de la Edificación, (5 ed.). Valencia (ISBN: 84-96602-206), (2006) pp. 21-37.

(10) UNE-EN 14411: 2007 Baldosas cerámicas. Definiciones, clasificación, características y marcado.

(11) Puig, R.; et al.: "Llibre didàctic d'Anàlisi del Cicle de Vida (ACV)" Xarxa temàtica Catalana d'ACV. Edición disponible digital http://mediambient.gencat.net/cat/empreses/ipp/ llibre acv.pdf (2002) p. 4.

(12) Minguillón Bengochea, M.C.: Tesis Doctoral. "Composición y fuentes del material particulado atmosférico en la zona cerámica de Castellón: Impacto de la introducción de las mejores técnicas disponibles". Universistat Jaume I, Castellón, 2007.

(13) Monfort, E.; Celades, I.; Sanfelix, V.; Gomar, S.: "Estimación de emisiones difusas de PM10 y rendimiento de Mejores Técnicas Disponibles 's en el sector cerámico". Bol. Soc. Esp. Ceram. Vidr., 48 (1), 15-24, 2009.

(14) Monfort, E.; García-Ten, J.; Celades, I.; Gomar, S.: Monitoring and possible reduction of HF in stack flue gases from ceramic tiles. J. Fluorine Chem., 2009.

(15) Plan Nacional Integrado de Residuos (PNIR) 2007-2015. Ministerio de Medioambiente, 2006.

(16) Paulsen, J.: Service life prediction for floor coverings. En: Lacasse, M.A.; Vanier, D.J. (Eds.) Durability of building materials and components. Ottawa: NRC, 1999, pp. 1467-1474.

(17) prEN 15804:2008 Sustanibility of construction Works - Environmental product declarations - Core rules for the Product Category of Construction Products.

(18) Product-Category Rules (PCR) for preparing an environmental declaration (EPD) for Building products, PCR 2006:02. Version 1.0. 2006-02-22. The Swedish Environmental Management Council. 